\section{Vehicle Fraud Detection Using Microscopy}

Joshua J. Kruger

South African Police Service Forensic Science Laboratory

In a criminal case, such as vehicle theft or vehicle hijacking, where a vehicle has been dismantled, the forensic scientist is many times faced with the problem of establishing the history of a specific auto body part. The normal method for doing this is by performing paint analysis. There are, however, a few shortcomings to paint analysis. In this paper another technique for determining the history of a body part is discussed, namely the comparison of surface replicas.

\section{INTRODUCTION}

In South Africa, vehicle theft or vehicle hi-jacking is one of the most frequently occurring crimes that the South African Police Service have to deal with. According to the South African Police Service Crime Information Management Centre, a vehicle is stolen or hi-jacked approximately every five minutes.

A big problem to the police is what happens to a vehicle directly after it has been stolen or hi-jacked. One of the following scenarios is sure to happen to such a vehicle

1. The vehicle is transported over the borders to a neighboring country.

2. The vehicle is re-painted.

3. The vehicle is taken to a "chop-shop".

A "chop-shop" is a place where stolen vehicles are dismantled. Parts of different vehicles are then reused on other vehicles. This makes it really difficult for a victim of such a crime to recognize his/her vehicle, as unique features on the vehicle might have been changed. Many times the South African Police Service Forensic Science Laboratory is asked to compare different body parts in order to determine whether they have originated from a specific vehicle. This is usually done by comparing paint samples. This offers good results only if a vehicle has been re-painted or sprayed, but not if the paint is original (i.e., as it was spray painted during in the manufacturing).

One very interesting case seemingly changed this muchused paint comparison technique.

\section{CASE BACKGROUND}

In this case, a man (hereafter referred to as $\mathrm{Mr}$. $\mathrm{X}$ ) who had bought a very expensive car could not afford to continue payments to the bank. After making only two payments, he stopped paying altogether. At that time he, with the help of a few skilled friends, dismantled his whole car. All the body parts were removed, the entire interior including the dashboard, was removed and even the engine and transmission were removed. $\mathrm{Mr}$. $\mathrm{X}$ then stashed all the parts and the stripped chassis with a friend and reported the car as stolen. An investigation was launched and when the car could not be found, a large sum of money was paid to $\mathrm{Mr}$. $X$ by the company where his car was insured. About one month after he received the money, Mr. $\mathrm{X}$, with the help of his skilled friends, one evening towed the stripped chassis (which still had the original wheels) and left it in a busy street in the centre of town.

Of course, the next morning the police found the "stolen" car; right under their noses. The car was subsequently impounded and later handed over to the insurance company, who then owned it.

On "hearing" this, Mr. $X$ contacted the insurance company and inquired if he could not buy the useless, stripped chassis back from them. After some deliberation, the insurance company agreed and the man bought back the chassis.

One of the employees at the insurance company, however, was very suspicious. He calculated that if $\mathrm{Mr} . \mathrm{X}$ would buy all the parts to re-build the car, it would cost him almost four times the price of a new car. He contacted the police and informed them of his suspicion.

A few days later, the police went to Mr. $X$ 's house to investigate. On their arrival the police was astonished to find that the car was almost completely rebuilt. Two body parts which were not yet built onto the chassis, were the two front fenders. Mr. $X$ produced invoices to "prove" that he bought them from a scrap metal dealer. The scrap metal dealer was a very good friend.

Now the big question was asked once again: "Can the forensic science trace evidence expert prove beyond doubt that the two front fenders found in the suspect's possession ("Mr. X" was now the suspect), were originally part of the now almost completely rebuilt car?"

\section{ANALYSIS}

Paint analysis, in this case, would not have been a satisfactory technique, as the paint on both the fenders and the body were original. On examining the fenders, I made a very interesting observation. Both fenders had brackets by which it would be bolted to the chassis. The brackets were very distinctive. They had a hole in the middle, through which a bolt goes and then it had a set of four nipples which actually made contact with the chassis, surrounding the hole (Figure 1). The contact area between each nipple and the chassis, was approximately $1-2 \mathrm{~mm}^{2}$. There were eight brackets on each fender.

On examining the chassis, I could see exactly where the sets of nipples of each bracket made contact with the chassis. I then decided to make surface replicas of all the brackets as well as the corresponding areas on the chassis. I did this by using MIKROSIL.***

MIKROSIL is a brownish paste, that comes in a toothpastelike tube. It is mixed with a catalyst and then applied to the surface to be replicated. Within 3-6 minutes it dries to form an elastic rubber-like replica. This is then peeled off and used for comparison.

\section{RESULTS}

Back at the laboratory, I examined the surface replicas using a LEICA DM C comparison macroscope at $320 \mathrm{X}$ total magnification. Each time the replica of one of the nipples was compared with the replica of the corresponding contact mark on the chassis. It was quite obvious that all the corresponding replicas were similar in size, form and characteristic pattern.

Figures 2 and 3 depicts two of these corresponding replicas (remember that the two replicas are mirror images).

I compiled a report as well as a photo album of all the corresponding replicas. This report and photo album were submitted to the court.

\section{PRESENTING THE EVIDENCE IN COURT}

Firstly, it should be mentioned that South Africa does not have a jury system like the United States of America. In our courts, there is usually only a judge and, in some cases, there might be one or two assessors. He/they are the ones who need to be convinced and make the ruling. One of the most difficult tasks, of course, is to convince a judge of the validity of any new technique. A positive point, at least, is that you only have to convince

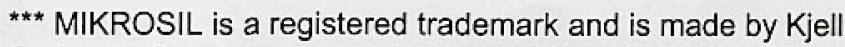 Carlsson, Sweden}

\section{Continued on page 10}




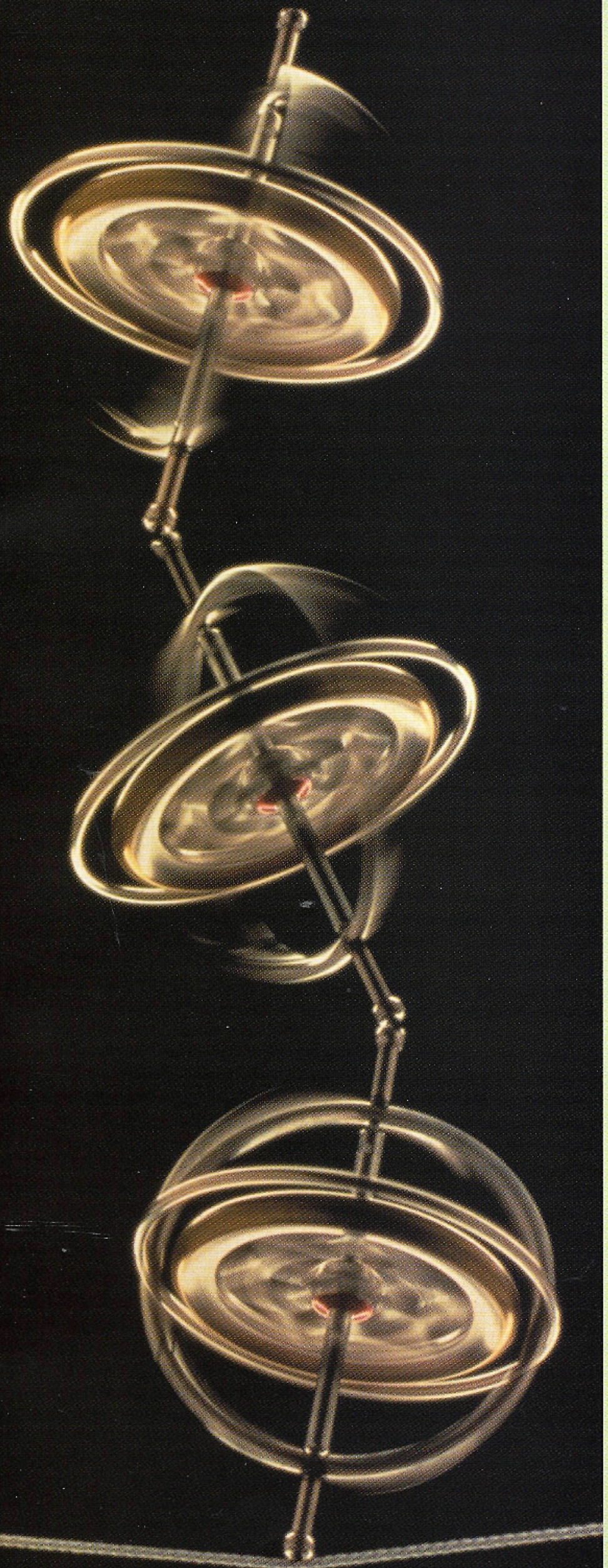

\section{Getting All Your Detectors} Working Together Can Be A Tough Balancing Act.

\section{That's Where Emispec Comes In.}

If balancing all components of your detectors has your head spinning, you should be talking to us.

You see, at Emispec Systems, Inc., we approach data acquisition differently. Instead of creating systems targeting one detector, we focus on integration. This concept can be applied equally to new and existing electron microscope installations. Core acquisition capabilities of our products include:

\section{- Digital scanning for STEM.}

- Digital EDX acquisition and analysis.

- EELS acquisition and analysis.

- CCD and TV imaging.

Integrated microscope control, imaging and spectroscopy allows automation of demanding experiments, such as spectrum imaging. Emispec enhances these capabilities with extensive on-line and off-line processing.

To find out how Emispec can help your lab keep in balance, visit our Web site today at www.emispec.com. See why we are fast becoming the leader in microscope detector technology solutions.

\section{Emispec}

Emispec Systems, Inc

2409 South Rural Road, Suite D

Tempe, Arizona 85282 USA

Phone: 480.894 .6443 - Fax: 480.894 .6458 Web: wnwemispec.com

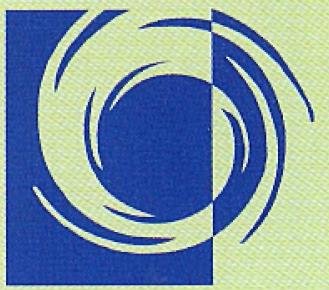

thinking beyond the box ${ }^{\top M}$ 


\section{Vehicle Fraud Detection Using Microscopy Continued from page 8}

one man and not an entire jury.

So, surely now came the most difficult part of my whole case ... presenting the evidence in court in an understandable way. First an attempt was made by the defense lawyer to discredit me. He reasoned that, while my affidavit stated that I had at that time seven years experience in chemistry, by definition what I had done in this case was not chemistry. It took me almost two days to convince the judge that chemistry and physics are inseparable and that I was actually competent to perform such analysis.

After this first onslaught, the normal cross-examination followed, which lasted almost forever. Following are a few of the questions I was asked, and my answers to them.

Q1: Why are some of the corresponding patterns not exactly the same size?

A1: MIKROSIL is elastic after it has dried. In order to examine

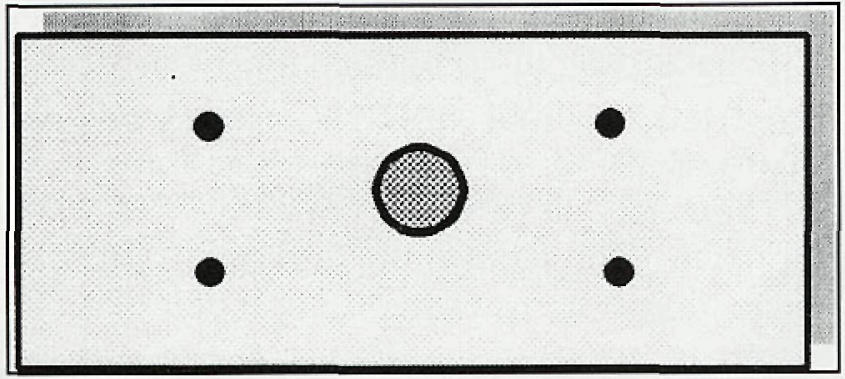

Figure 1. A drawing of the fender bracket.

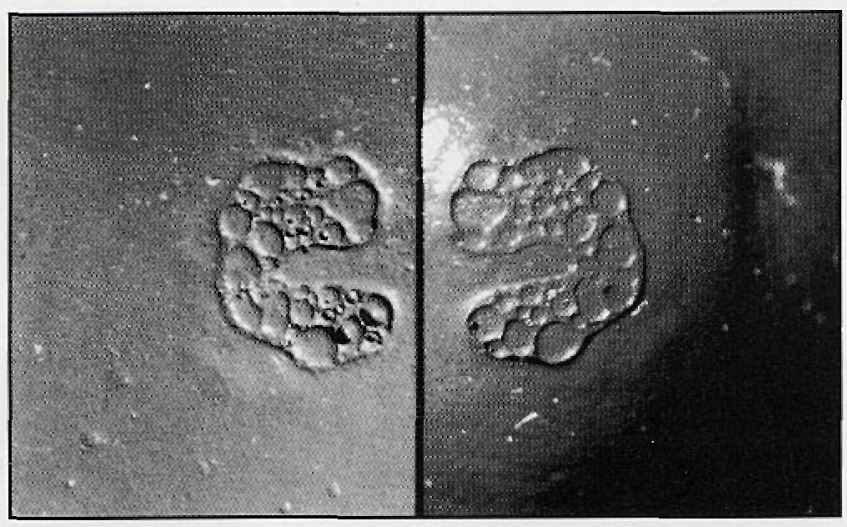

Figure 2. Corresponding mirror image replicas from the chassis and bracket.

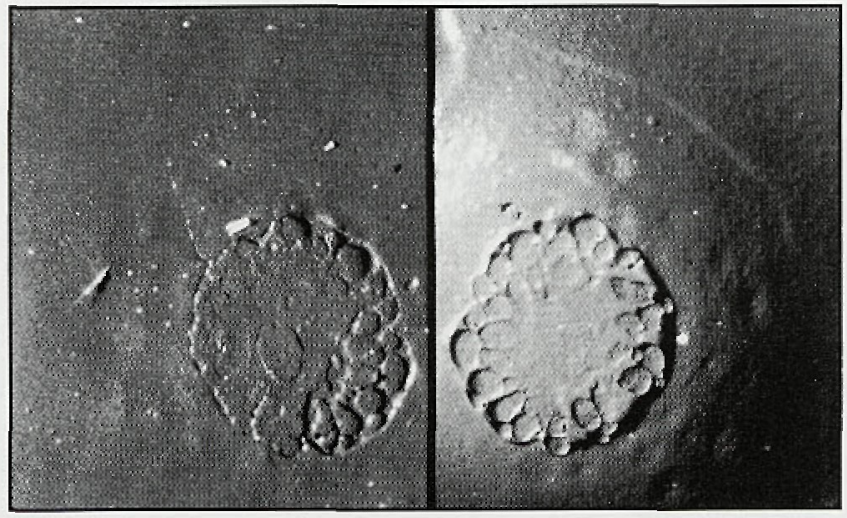

Figure 3. Replicas from another area of the same chassis and bracket. the replicas, they are stretched open and pinned down on piece of polystyrene. It is quite possible that one replica is stretched just slightly more than the corresponding one. This will, of course, cause a small variation in size and shape.

Q2: Why don't two corresponding replicas look exactly the same? A2: As it was stated by Fisher" "each replication process causes loss of detail" and by Bikerman "According to the modern science of adhesive joints, a replica can not be removed cleanly from a substrate by mechanical means. Never is the surface of a replica a perfect mirror image of tile initial surface"

This does not mean that a replica and an original surface are incomparable, but merely that slight changes may occur. In this case the fault is doubled, as we are comparing two replicas and not a replica with an original surface.

\section{Q3: What actually causes the corresponding marks?}

A3: During the manufacturing process of most vehicles, the body parts are fitted to the chassis just before it is dipped into an electroplating bath. Wherever two objects are in close contact, like where two nipples of the fenders are in contact with the chassis, capillary force will cause some paint to be drawn in between the two objects. As the paint dries, a unique pattern forms. When a body part is then removed, the unique pattern will show on both object surfaces.

Q4: Is it not possible that the process of manufacturing cars is so precise, that two different cars could have the same "unique pattern" on a specific point?

A4: NO!!

As I expected, there was a lot of skepticism from the judge and, of course, from the defense lawyer. Only after we actually went to the scene, where I showed the court exactly how I had taken the samples and how I analyzed them, did the judge accept my testimony. I testified on five different occasions in a time span of more than a year.

The suspect was subsequently found guilty of fraud and was sentenced accordingly. Similar cases have since been solved, in the same manner, by this laboratory.

\section{CONCLUSION}

Again it is proven beyond doubt, that forensic science cannot exist without microscopy. Here, with the use of surface replication and light microscopy, infallible evidence led to the prosecution of a criminal. Surface replication, is also proved to be an excellent technique for determining the history of vehicle body parts. A very informative article, which has since been published, is by Gummer and Walsh ${ }^{3}$.

No member of the "Blind Chemists Society"4 could have solved this case, or will ever be able to solve similar cases.

1. Fisher, R.B. Applied Electron Microscopy; Indiana University Press, Bloomington, U.S.A., 1953, p 164.

2. Bikerman, 1.1. The Science of adhesive joints; Academic Press, New York, U.S.A., 1968, pp 137-150.

3. Cummer, T. and Walsh, K., Matching vehicle parts back to the vehicle: a study of the process; Forensic Science International, 1996, 82, pp 89-97.

4. Stoney, D.A. Welcome to the Blind Chemists Society; Microscope 1996, 44 (1), iii.

Reprinted from The Microscope, Volume 47, Fourth Quarter, 1999 from The McCrone Research Institute. 


\section{Section-One: Analogies}

1) Film is to the KODAK MDS 290 as
A) Typewriter is to Word Processor
B) Magnifying Glass is to Microscope
C) Abacus is to Calculator
D) Pony Express is to E-Mail
E) All of the Above

see answer below
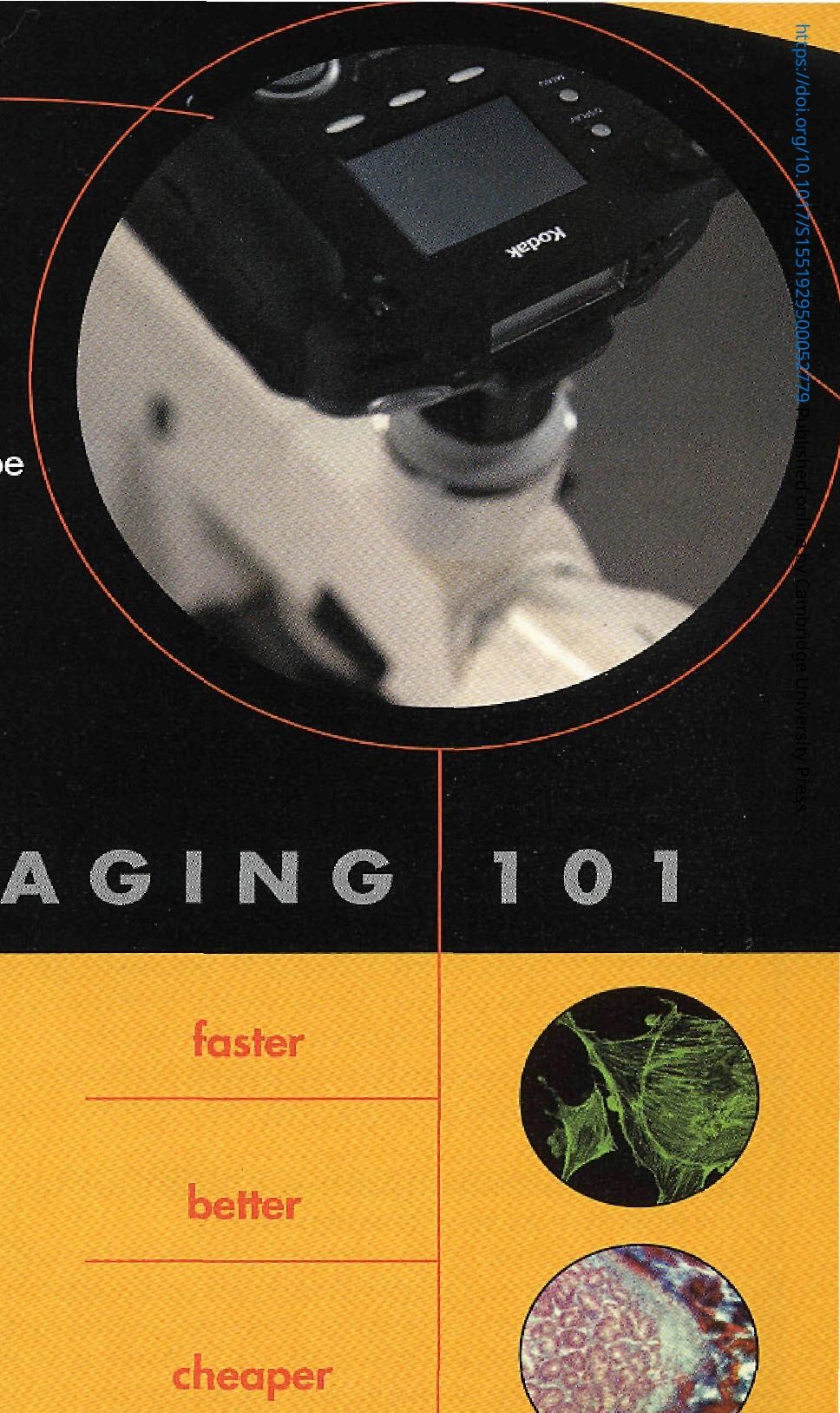

\section{The New Microscopy Documentation System 290}

The revolutionary digital imaging tool for microscopy documentation. Versatile and
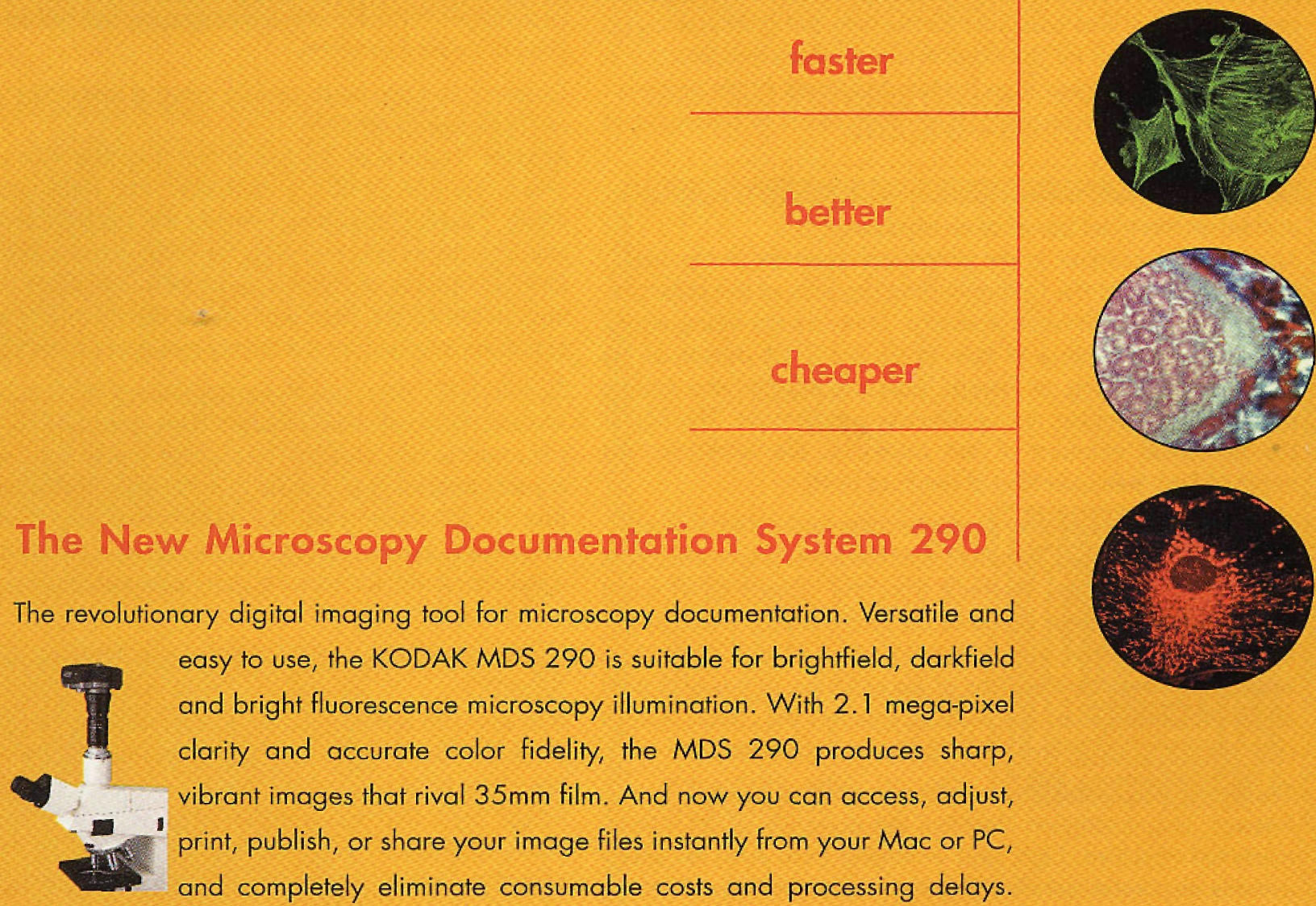

Plus, the MDS 290 can be used on or off the microscope for micro/macro or general lab photography. With its low price tag and unmatched performance, your lab can't afford to be without one.

For more information, visit www.kodak.com/go/mds290w 